Gut and Liver, Vol. 10, No. 1, January 2016, pp. 12-26

\title{
Mass Eradication of Helicobacter pylori to Prevent Gastric Cancer: Theoretical and Practical Considerations
}

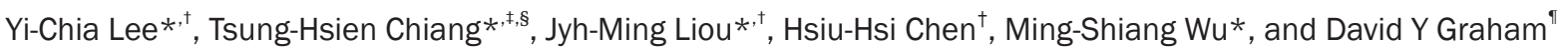 \\ ${ }^{*}$ Department of Internal Medicine, National Taiwan University College of Medicine, ${ }^{\dagger}$ Institute of Epidemiology and Preventive Medicine, \\ National Taiwan University College of Public Health, ${ }^{\ddagger}$ Graduate Institute of Clinical Medicine, National Taiwan University College of Medicine, \\ ${ }^{s}$ Department of Integrated Diagnostics and Therapeutics, National Taiwan University Hospital, Taipei, Taiwan, and "Department of Medicine, \\ Michael E. DeBakey VA Medical Center, and Baylor College of Medicine, Houston, TX, USA
}

Although the age-adjusted incidence of gastric cancer is declining, the absolute number of new cases of gastric cancer is increasing due to population growth and aging. An effective strategy is needed to prevent this deadly cancer. Among the available strategies, screen-and-treat for Helicobacter pylori infection appears to be the best approach to decrease cancer risk; however, implementation of this strategy on the population level requires a systematic approach. The program also must be integrated into national healthcare priorities to allow the limited resources to be most effectively allocated. Implementation will require adoption of an appropriate screening strategy, an efficient delivery system with a timely referral for a positive test, and standardized treatment regimens based on clinical efficacy, side effects, simplicity, duration, and cost. Within the population, there are subpopulations that vary in risk such that a "one size fits all" approach is unlikely to be ideal. Sensitivity analyses will be required to identify whether the programs can be utilized by heterogeneous populations and will likely require adjustments to accommodate the needs of subpopulations. (Gut Liver 2016;10:12-26)

Key Words: Population screening; Helicobacter pylori; Eradication; Stomach neoplasms

\section{INTRODUCTION}

Gastric cancer is the fifth most common cancer in the world, with the majority of cases arising in East Asia. ${ }^{1}$ The ageadjusted incidence of gastric cancer has steadily declined, not only because of improvements in sanitation and hygiene, but also because the eradication of Helicobacter pylori has become a common clinical practice in the treatment of peptic ulcers. ${ }^{2}$ Nonetheless, the absolute number of new cases is unchanged in high-risk areas because the population is increasingly elderly, and a larger proportion of persons has been exposed to risk factors for decades. ${ }^{3}$ Gastric cancer is characterized by rapid progression and a high case-fatality rate when diagnosed at an advanced stage. Prevention of acquisition of an $H$. pylori infection or treatment of $H$. pylori before the development of atrophic gastritis are the best means of reducing or eliminating gastric cancer. It is of paramount importance to design an effective cancer prevention strategy at the population level.

\section{STRATEGY TO PREVENT GASTRIC CANCER}

The traditional approach for prevention of gastric cancer is one of secondary prevention and emphasizes the use of endoscopy to identify early cancer and provide curative treatment. ${ }^{4}$ In 2005, the Nobel Prize in Physiology or Medicine was awarded jointly to Barry Marshall and Robin Warren for their discovery of the $H$. pylori and its role in gastritis and peptic ulcer disease. ${ }^{5}$ Because chronic inflammation is a common risk factor for carcinogenesis, ${ }^{6}$ it was suggested that primary prevention of gastric cancer could be achievable through a screen-and-treat strategy for $H$. pylori infection. Subsequently, a growing number of studies have aimed to investigate this topic. In December 2013, a Working Group Meeting was hosted in Lyon, France by the International Agency for Research on Cancer (IARC) to review the accumulated evidence that supported the use of mass eradication of $H$. pylori as a strategy to prevent gastric cancer. ${ }^{7}$ On the basis of the favorable results from the randomized controlled trials (RCTs) and observational studies, the expert working group confirmed that this strategy was effective; a recom-

Correspondence to: Ming-Shiang Wu

Department of Internal Medicine, National Taiwan University Hospital, No. 7, Chung-Shan South Road, Taipei 10002, Taiwan

Tel: +886-2-23123456, Fax: +886-2-23412775, E-mail: mingshiang@ntu.edu.tw

Received on February 24, 2015. Accepted on June 29, 2015.

pISSN 1976-2283 eISSN 2005-1212 http://dx.doi.org/10.5009/gnl15091

@) This is an Open Access article distributed under the terms of the Creative Commons Attribution Non-Commercial License (http://creativecommons.org/licenses/by-nc/4.0) which permits unrestricted non-commercial use, distribution, and reproduction in any medium, provided the original work is properly cited. 
mendation has been made to encourage health-care agencies to include such a strategy in national cancer control programs. In January 2014, a global consensus meeting was held in Kyoto, Japan to evaluate the management of $H$. pylori-related gastritis, a precursor to gastric cancer. ${ }^{8}$ Similarly, consensus has been reached in the conclusion that eradication of $H$. pylori can prevent gastric cancer and the recommendation that all carriers of $H$. pylori should be treated to eradicate this pathogen.

To summarize, the major question currently is no longer whether we should eradicate $H$. pylori. Instead, our attention should be focused on how we can accomplish this goal on the population level, ${ }^{9}$ i.e., identifying those with $H$. pylori infection among the asymptomatic population and eradicating their $H$. pylori infection before the development of gastric cancer. In addition, it would also be desirable to identify persons with gastric cancer at the preclinical detectable phase (PCDP). Important issues that must be resolved to develop a strategy to propose to policy-makers/stakeholders for funding/administrative support include: how to design and organize a screening program, how to track outcomes, and how to use resources most efficiently.

In Taiwan, programmatic gastric cancer prevention was started in 2004 for a high-risk population on an offshore island (i.e., Matsu Island Gastric Cancer Prevention Program; Trial registration number: NCT00155389) utilizing the strategy of mass eradication of $\mathrm{H}$. pylori. ${ }^{10}$ Based on the favorable results of that program over a 10-year follow-up period, the concept of this preventive strategy has been disseminated to the healthcare authorities in Taiwan. Starting in 2012, a preventive program using a modified screening design and eligibility criteria was implemented in a general population in Changhua County ${ }^{11}$ (i.e., Changhua County Gastric Cancer Prevention Program; Trial registration number: NCT01741363), Taiwan. Since then, the staged implementation of this policy has been expanded gradually to other counties and cities. This report discusses the rationale and workflow of the screen-and-treat strategy for $H$. pylori infection with reference to these two population-based programs with special emphasis on how to design and implement such a strategy on the population level.

\section{REQUIREMENTS FOR A GASTRIC CANCER PREVENTION PROGRAM TO BE PROPOSED TO POLICY-MAKERS/ STAKEHOLDERS FOR FUNDING}

Despite the importance of $H$. pylori infection in the development of gastric cancer, few screen-and-treat programs have begun. One reason for this is the mistaken impression that gastric cancer will soon disappear making gastric cancer less important than other public health issues. ${ }^{3}$ One can assess the appropriate-

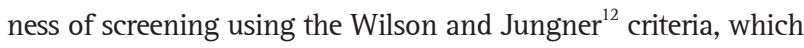
are considered to be the gold standard to judge the feasibility of a screening program. According to Wilson and Jungner, (1) the condition should be an important health problem; (2) there should be a recognizable early pre-symptomatic stage and an accepted treatment; and (3) facilities for diagnosis and treatment should be available.

\section{Is gastric cancer an important health problem?}

When a population harbors a high disease burden, asymptomatic members of the population are likely to be aware of the disease and thus may participate in screening. In populations with a high disease burden, the positive predictive value (PPV) of the test will also be high. On a global scale, the IARC has predicted that the annual number of new cases of gastric cancer is expected to increase or remain at a constant level by 2030 (Table 1). ${ }^{7}$ This prediction is consistent with the experience in Taiwan, where gastric cancer is the seventh most common cancer and the sixth most deadly cancer. Every year in Taiwan, there are around 3,800 new cases with an incidence of approximate 17 per 100,000 person-years; approximately 2,300 persons die from gastric cancer each year. ${ }^{13}$ Although the age-standardized incidence of gastric cancer is declining, the absolute numbers of incident cases are stationary or even slightly increased; by contrast, the incidence of colorectal cancer is rapidly increasing. Following the nationwide screening program launched in 2004, its casefatality rate (ratio of mortality/incidence) is 0.35 , which is much lower than that of gastric cancer (0.59), reflecting the urgent need to prevent gastric cancer in Taiwan.

\section{Are there a recognizable early presymptomatic stage and an accepted treatment?}

Understanding the natural history of a particular type of cancer is crucial in the design of an effective intervention. As shown in Fig. 1A, the natural course of a cancer can be separated into three phases: (1) the carcinogenic phase (i.e., increased cancer risk due to carcinogen exposure); (2) the PCDP (i.e., early-stage, presymptomatic cancer); and (3) the clinical phase (i.e., advanced-stage, symptomatic cancer). Cancers at the PCDP are the targets of screening, although not every type of cancer is amenable to detection by screening. The longer the PCDP (i.e., the time between cancer onset and clinical symptoms), the

Table 1. Predicted Burden of Gastric Cancer, 2012-2030

\begin{tabular}{ccc}
\hline Year & Demographic effect & Demographic effect with -2.0\% APC \\
\hline 2012 & 0.95 & 0.95 \\
2015 & 1.03 & 0.97 \\
2020 & 1.17 & 1.00 \\
2025 & 1.34 & 1.03 \\
2030 & 1.52 & 1.06 \\
\hline
\end{tabular}

APC, annual percentage change.

Adapted from IARC Helicobacter pylori Working Group. Helicobacter pylori eradication as a strategy for preventing gastric cancer (IARC Working Group Reports, No. 8). Lyon: International Agency for Research on Cancer; $2014 .^{7}$ 


\section{A}

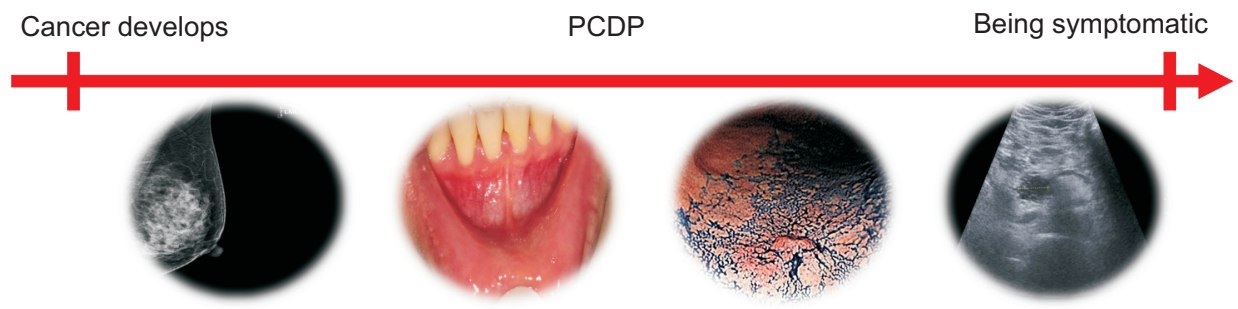

Breast cancer (4.1)

Oral cancer (2.9)

Gastric cancer (1.4) Pancreatic cancer (0.4)
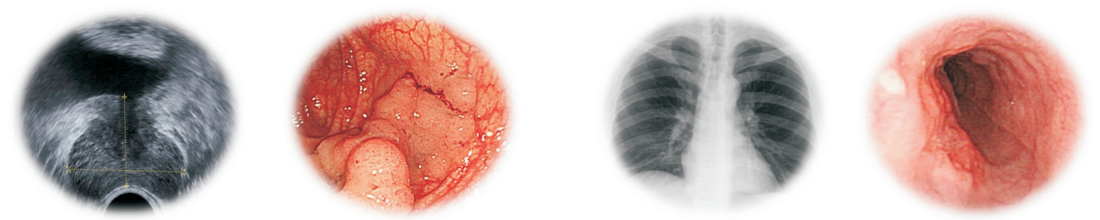

Prostate cancer (3.7)

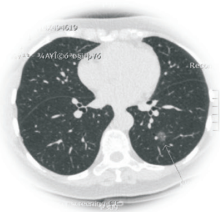

Lung cancer (?)

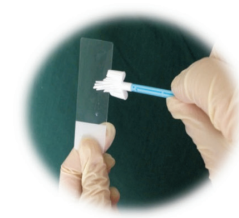

Cervical cancer (3.6)
$(2.9)$

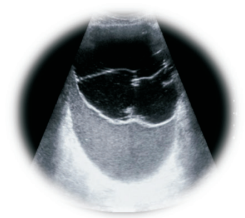

Ovarian cancer (2.6)

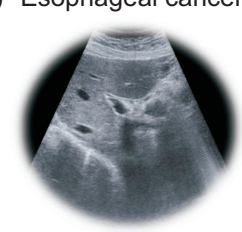

Liver cancer (0.6)

B

Risk factors for primary prevention

Cancer develops PCDP

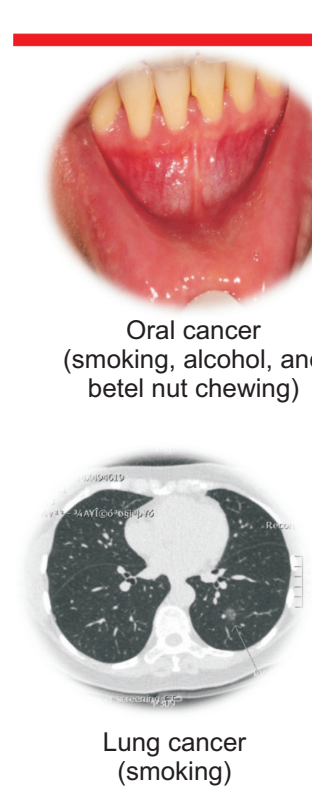

(smoking)

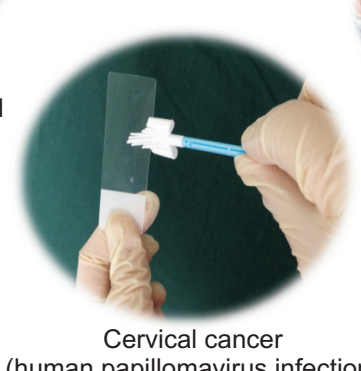

(human papillomavirus infection)

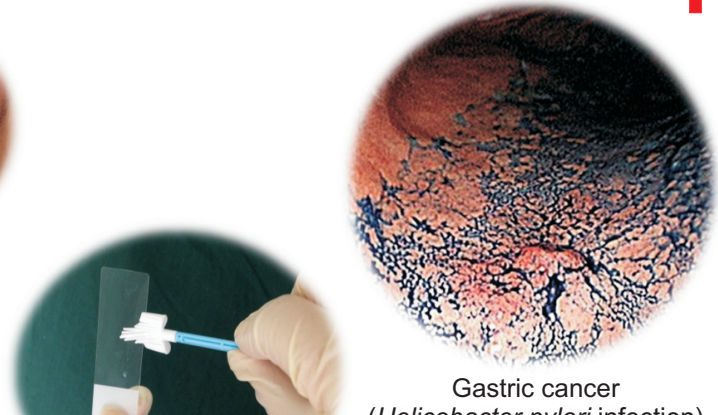

(Helicobacter pylori infection)

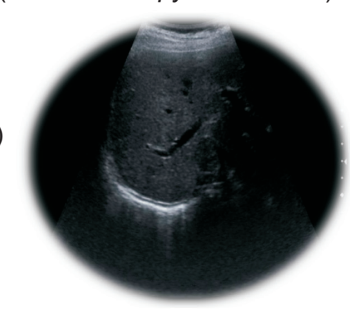

Liver cancer

(hepatitis B and C viral infection)
Fig. 1. The preventable phase of a cancer includes (A) the preclinical detectable phase (PCDP; the number in parenthesis indicates the length of the PCDP in years for a specific cancer) and (B) the carcinogenic phase related to exposure to risk factors (well-known risk factors for the development of a specific cancer are shown in parentheses). longer the lead time (i.e., the time between cancer detection and clinical symptoms); when a diagnosis is made by screening, prolonged survival (or cure) may be possible. The PCDPs of various cancers have been estimated in the work of Bray et al. ${ }^{14}$ using the prevalence/incidence ratios. In cancers with very short PCDPs, a screening test may diagnose the cancer earlier but with no effect on the outcome. The apparent effect is the so-called lead time bias. By contrast, in cancers with very long
PCDPs (e.g., prostate cancer screened by prostate specific antigen ${ }^{15}$ ), the screening test may detect indolent cancers which may never cause clinical symptoms in the remaining lifetime of the patient, thus raising the issue of overdiagnosis. Obviously, the length of PCDP is not fixed, which is related to the detectability of a screening tool. If a screening tool can identify cancerous foci earlier, the PCDP can be prolonged $;{ }^{16}$ the example is the use of low-dose computed tomography, instead of chest X- 
ray, to screen lung cancer. ${ }^{17}$

The mean PCDP of gastric cancer is relatively short, about 1.4 years, ${ }^{14}$ which may explain why a 1 - to 2 -year screening interval is generally recommended for endoscopic surveillance in high risk groups. In fact, upper endoscopy is not an ideal massscreening tool for gastric cancer as it is expensive, labor-intensive, and not without risk. In addition, the results are subject to interoperator variation so interval cancers ${ }^{18}$ (i.e., symptomatic cancer diagnosed during the interscreening interval) are not infrequent. By contrast, colorectal cancer, which has a PCDP of approximate 3 years, is suitable for biennial screening with the noninvasive fecal immunochemical testing, which also has the advantage of a high yield with positive tests. ${ }^{19}$

A number of cancers (Fig. 1B) have well-established risk factors such that elimination of, or protection from, these factors can prevent cancer development. Population-based vaccination against viruses that causes cervical cancer ${ }^{20}$ or liver cancer ${ }^{21}$ has been shown to be effective in reducing the subsequent cancer risk. In contrast, $H$. pylori infection has not received this kind of attention, despite its well-recognized causative role in gastric cancer. If $H$. pylori can be removed from the population, it has been estimated that approximately 75\% of gastric cancer would be eliminated. ${ }^{22}$ This is likely an underestimate as early estimates of causation were based on serology, which underestimated the proportion of gastric cancers due to $H$. pylori; in addition, such a gastric cancer prevention strategy is supported by studies in a real-world setting (Fig. 2), ${ }^{10,23-30}$ with favorable results for either premalignant lesions ${ }^{10,24-26,28,29}$ or actual gastric cancer. ${ }^{10,23,27,30}$ Furthermore, by pooling six RCTs, a recent meta-analysis con- sistently showed that the eradication of $H$. pylori can provide a significant risk reduction of 34\% for gastric cancer in asymptomatic $H$. pylori infected individuals. ${ }^{31}$ For patients diagnosed with early gastric cancer who underwent endoscopic resection, another meta-analysis based on 13 studies, including two RCTs and 11 cohort studies, also showed a significant risk reduction of 58\%. ${ }^{32}$ Because premalignant gastric lesions are expected to be prevalent in the latter group, these observations suggest that it is never too late to eradicate $H$. pylori.

The decision to eradicate $H$. pylori to prevent gastric cancer is a public health decision where the problem must be weighed against the other pressing issues and the budget. The risks of a persistent infection include progressive exponential increase in gastric cancer risk, risk of developing a peptic ulcer (approximately 1 in 6), and among those an ulcer complication (approximately 1 in 4); this is also the reservoir of infection responsible for transmission (i.e., H. pylori is a transmissible infectious disease). In addition to the elimination of gastric cancer and peptic ulcer disease, there are many potential advantages of eradication (Table 2), including the mucosa associated lymphoid tissue lymphoma, functional dyspepsia, atrophic gastritis, vitamin $\mathrm{B}_{12}$ deficiency, iron deficiency anemia, idiopathic thrombocytopenic purpura, and so forth. ${ }^{33}$ Ideally, population-wide eradication would be done as it is once-off that would eliminate these diseases. However, new cases would continue the population as most immigrants are likely to be infected. Case finding and follow-up of individuals subsequently discovered to be infected would be needed as is done for many transmissible infectious diseases.

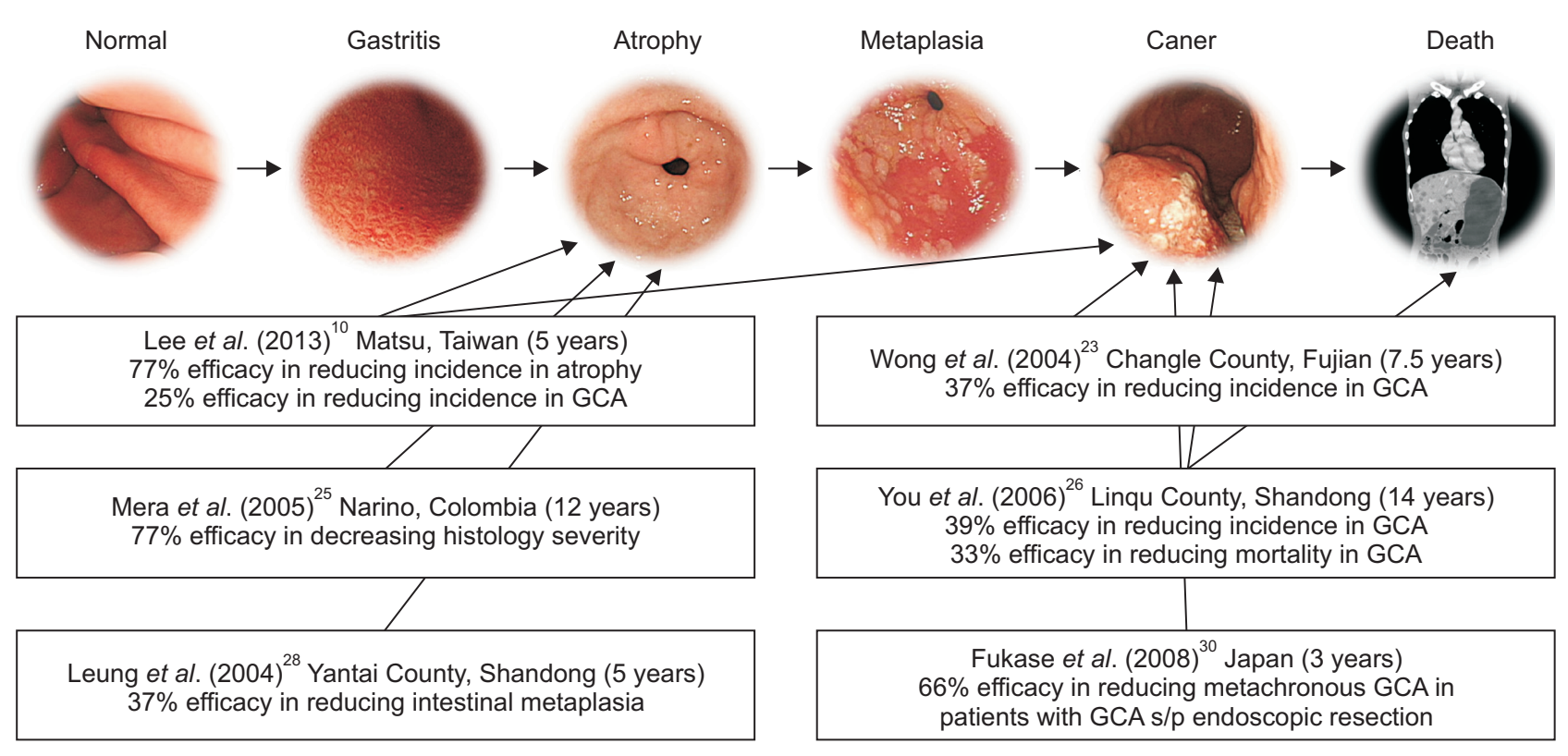

Fig. 2. The efficacy/effectiveness of the population-based interventions for prevention of gastric cancer according to the surrogate end-points of premalignant gastric lesions and primary end-points of gastric cancer incidence and mortality in the Correa's multistate model. GCA, gastric cancer; s/p, status post. 
Table 2. Benefit of Helicobacter pylori Eradication on Human Health

\begin{tabular}{lc}
\hline \multicolumn{1}{c}{ Benefit of $H$. pylori eradication } & Evidence level \\
\hline Gastric cancer & Ic \\
Peptic ulcer disease & Ia \\
MALT lymphoma & 1a \\
Functional dyspepsia & Ia \\
Atrophic gastritis & 1a \\
Vitamin $\mathrm{B}_{12}$ deficiency & $3 \mathrm{~b}$ \\
Iron deficiency anemia & $1 \mathrm{a}$ \\
Idiopathic thrombocytopenic purpura & 1b \\
\hline
\end{tabular}

The system for evidence levels: 1a: systematic review of randomized controlled trials (RCTs) with homogeneity; $1 \mathrm{~b}$ : individual RCT with narrow confidence interval; 1c: individual RCT with risk of bias; 2a: systematic review of cohort studies with homogeneity; $2 \mathrm{~b}$ : individual cohort study; 2c: noncontrolled cohort studies/ecological studies; 3a: systematic review of case-control studies with homogeneity; 3b: individual case-control study; 4: case-series; 5: expert opinion. Adapted from Malfertheiner P, et al. Gut 2012;61:646-664. ${ }^{33}$

MALT, mucosa associated lymphoid tissue.

\section{Are facilities for diagnosis and treatment available?}

Reliable tests are available to diagnose $H$. pylori infections including histologic evaluation of the gastric mucosa, rapid urease test, culture, urea breath test (UBT), stool antigen test (SAT), IgG anti-H. pylori serology, and so forth. Noninvasive tests are preferred for population screening. . $^{33,34}$ Both the UBT and SAT are $>90 \%$ sensitive and specific; however, both are relatively expensive and require patient cooperation. ${ }^{35,36}$ IgG anti-Helicobacter serology is cheap and if validated for that population, is relatively accurate. The main disadvantage of serology is that the test may remain positive after the infection is cured. ${ }^{37}$ One way to utilize serology is to confirm positivity by using a second noninvasive test (e.g., UBT or SAT) on those with positive results.

During screening, the PPV of a screening test is the key process indicator to support the effectiveness of a program. ${ }^{38}$ In a screen-and-treat strategy, the PPV is dependent on both the performance of $H$. pylori testing and the prevalence rate of $H$. pylori in a specific population. The equation can be expressed as follows: ${ }^{11}$

$$
\mathrm{PPV}=\frac{(\text { sensitivity })(\text { prevalence })}{\text { (sensitivity)(prevalence)+(1-specificity)(1-prevalence) }}
$$

In a population with a $H$. pylori prevalence of 80\% (e.g., Latin American), ${ }^{39,40}$ the PPVs for serological testing and SAT are estimated at 94\% and 99\%, respectively, which shows a minimal difference. Thus, the choice between two tests may depend on the infrastructure of a program and the available budget. When the prevalence is $40 \%$ (e.g., East Asia), ${ }^{41}$ the PPVs for serological testing and SAT are estimated to be $73 \%$ and 95\%, respectively, showing a significant difference in performance between the two tests. Taking the screen-and-treat programs in Taiwan as examples, the prevalence of $H$. pylori was 60\% and 35\% for the populations residing in Matsu Island and Changhua County, respectively, before mass screening. The ${ }^{13} \mathrm{C}$-UBT has been adopted in the Matsu population, given a small high-risk population with adequate funding support and manpower, ${ }^{10,42}$ while SAT was selected for the Changhua population for a large population with limited manpower and infrastructure in delivery of the screening test. ${ }^{11}$

Highly effective antibiotic regimens are available for most populations. The success of antimicrobial therapy for a bacterial infection depends largely on the presence of susceptibility to the antibiotic or antibiotics and the adherence of the patients to the therapy. With a multiple-drug therapy, one only needs to know the antibiotic-resistance pattern and the eradication rates for each subgroup in relation to the antibiotics (e.g., susceptible to all, resistant to one antibiotic, etc). ${ }^{43}$ With these data, one can create a reliable model to estimate the treatment outcome with combination of a proton pump inhibitor, amoxicillin, clarithromycin, and metronidazole. The on-line calculator available at https://hp-therapy.biomed.org.tw/. ${ }^{44}$ In brief, for a regimen using amoxicillin, clarithromycin, and metronidazole, the treatment outcome can be predicted based on the summarized eradication rates according to the percentages of strains dual sensitive, single resistant, and dual resistant to clarithromycin and metronidazole, assuming that the amoxicillin resistance is a rare event, which can be summarized as: ${ }^{45}$ (\% success with all-susceptible strains) $\times($ proportion with all-susceptible infections $)+(\%$ success with clarithromycin-susceptible strains) $\times$ (proportion with clarithromycin-susceptible infections)+(\% success with metronidazole-susceptible strains) $\times$ (proportion with metronidazole-susceptible infections)+(\% success with dual resistant strains) $\times$ (proportion with dual resistant strains).

Based on this model, the reported outcomes of the twoantibiotic and three-antibiotic regimens can be predicted by the prevalence of antibiotic resistance in a given population (Table $3) ;^{44-58}$ the predicted values are indeed comparable to the observed ones. The results showed that triple therapy for 14 days may provide an incremental efficacy of about 8\% as compared with 7 days' regimen, while four-drug regimens for 14 days can provide an incremental efficacy of about $7 \%$ as compared with 14-day triple therapy.

An effective program will require effective therapies. For most populations, it is possible to identify two alternatives that are highly effective when given empirically. Patients can then be assigned to therapy using a checklist to identify those likely to fail (e.g., use of both clarithromycin and metronidazole in the past). As a general rule, the 14-day therapy provides the highest treatment success. ${ }^{45}$ The local patterns of antibiotic resistance in the general population should be collected before the implementation of a mass eradication program. In addition, special treatment centers would be needed to offer the susceptibility-based 
Table 3. Estimation of the Efficacy of Triple Therapy and Sequential Therapy in the First-Line Treatment of Helicobacter pylori Infection

\begin{tabular}{|c|c|c|c|c|c|}
\hline Author (year), area & Regimen, day & $\begin{array}{l}\text { Prevalence of } \\
\text { clarithromycin } \\
\text { resistance }\end{array}$ & $\begin{array}{c}\text { Prevalence of } \\
\text { metronidazole } \\
\text { resistance }\end{array}$ & $\begin{array}{c}\text { Observed } \\
\text { efficacy }\end{array}$ & $\begin{array}{l}\text { Expected } \\
\text { efficacy }\end{array}$ \\
\hline \multirow[t]{3}{*}{ Zullo et al. $(2003)^{47}$, Italy } & Triple therapy, 7 & $4.4(6 / 137)$ & $27(37 / 137)$ & 77 & 88 \\
\hline & Sequential therapy, 10 & $6.7(9 / 135)$ & $26.7(36 / 135)$ & 95 & 89.1 \\
\hline & Sequential therapy, 14 & - & - & - & 93.4 \\
\hline \multirow[t]{3}{*}{ Romano et al. $(2003)^{48}$, Italy } & Triple therapy, 7 & $12.5(8 / 75)$ & $22.5(16 / 75)$ & 79.4 & 84.8 \\
\hline & Sequential therapy, 10 & - & - & - & 87.9 \\
\hline & Sequential therapy, 14 & - & - & - & 91.7 \\
\hline \multirow[t]{3}{*}{ Vaira et al. $(2007)^{49}$, Italy } & Triple therapy, 10 & $18.8(21 / 112)$ & $19.6(22 / 112)$ & 79 & 82.3 \\
\hline & Sequential therapy, 10 & $7.3(9 / 123)$ & $28.5(35 / 123)$ & 93 & 88.6 \\
\hline & Sequential therapy, 14 & - & - & - & 93.1 \\
\hline \multirow[t]{4}{*}{ Demir et al. (2009) $)^{50}$, Turkey } & Triple therapy, 14 & $64.3(36 / 56)$ & - & 42.9 & 65.2 \\
\hline & Triple therapy, 14 & $35.7(20 / 58)$ & - & 79.3 & 76 \\
\hline & Sequential therapy, 10 & - & - & - & 80.7 \\
\hline & Sequential therapy, 14 & - & - & - & 83.4 \\
\hline \multirow[t]{3}{*}{ Romano et al. $(2010)^{51}$, Italy } & Triple therapy, 14 & - & - & - & 81.3 \\
\hline & Sequential therapy, 10 & $21.8(12 / 55)$ & $25.5(14 / 55)$ & 82.8 & 84.7 \\
\hline & Sequential therapy, 14 & - & - & - & 88.2 \\
\hline \multirow[t]{3}{*}{ Wu et al. (2010) ${ }^{52}$, Taiwan } & Triple therapy, 14 & - & - & - & 87.5 \\
\hline & Sequential therapy, 10 & $6.6(11 / 167)$ & $33.5(56 / 167)$ & 93.1 & 88 \\
\hline & Sequential therapy, 14 & - & - & - & 93 \\
\hline Sirimontaporn et al. (2010) ${ }^{53}$, & Triple therapy, 14 & - & - & - & 87.2 \\
\hline \multirow[t]{2}{*}{ Thailand } & Sequential therapy, 10 & $6.1(7 / 114)$ & - & 92.2 & 89.6 \\
\hline & Sequential therapy, 14 & - & - & - & 93.8 \\
\hline Yakoob et al. $(2010)^{54}$, & Triple therapy, 14 & $33.3(30 / 92)$ & $48(44 / 92)$ & 67 & 77.7 \\
\hline \multirow[t]{2}{*}{ Pakistan } & Sequential therapy, 10 & - & - & - & 78.8 \\
\hline & Sequential therapy, 14 & - & - & - & 82.9 \\
\hline \multirow[t]{3}{*}{ Hsu et al. $(2011)^{55}$, Taiwan } & Triple therapy, 14 & - & - & - & 87.7 \\
\hline & Sequential therapy, 10 & - & - & - & 87.9 \\
\hline & Sequential therapy, 14 & $6.1(4 / 66)$ & $34.8(23 / 66)$ & 93.9 & 93.1 \\
\hline Malfertheiner et al. $(2011)^{56}$, & Triple therapy, 7 & $19.1(25 / 131)$ & $31.3(41 / 131)$ & 70 & 82.6 \\
\hline \multirow[t]{2}{*}{ Europe } & Sequential therapy, 10 & - & - & - & 84.7 \\
\hline & Sequential therapy, 14 & - & - & - & 88.9 \\
\hline Mahachai et al. $(2011)^{57}$, & Triple therapy, 14 & - & - & - & 85.3 \\
\hline \multirow[t]{2}{*}{ Thailand } & Sequential therapy, 10 & $11.3(17 / 151)$ & - & 94 & 88 \\
\hline & Sequential therapy, 14 & - & - & - & 92 \\
\hline \multirow[t]{3}{*}{ Liou et al. $(2013)^{44}$, Taiwan } & Triple therapy, 14 & $11.5(21 / 183)$ & $26.2(48 / 183)$ & 87.1 & 85.9 \\
\hline & Sequential therapy, 10 & $9.4(18 / 192)$ & $24.0(46 / 192)$ & 90.5 & 88.6 \\
\hline & Sequential therapy, 14 & $9.4(16 / 177)$ & $22.0(39 / 177)$ & 94.4 & 92.6 \\
\hline Molina-Infante et al. $(2013)^{58}$, & Hybrid therapy, 14 & $23.5(16 / 68)$ & $33.8(23 / 68)$ & 92 & 88.2 \\
\hline Italy and Spain & Concomitant therapy, 14 & $23.5(16 / 68)$ & $33.8(23 / 68)$ & 96.1 & 88.2 \\
\hline
\end{tabular}

Data are presented as percentage (number/total number). All efficacy estimates for anti-H. pylori therapy are 14 days in duration. Modified from Liou JM, et al. Lancet 2013;381:205-213. ${ }^{44}$

therapy for difficult-to-cure cases. In Taiwan, the regimens to be considered for most patients are triple therapy, concomitant therapy, and sequential therapy all for 14 days. Treatment fail- ures and penicillin allergic patients would receive levofloxacinbased therapy, bismuth quadruple therapy, or susceptibilitybased therapy. The considerations for primary therapy include 
cost, effectiveness, and side effects. Concomitant therapy will always be equal or superior to sequential therapy but has higher cost. Sequential therapy is also more complicated but this can be eliminated by prepackaged drugs.

\section{DESIGNING AN ORGANIZED PROGRAM FOR PREVEN- TION OF GASTRIC CANCER}

After standardization of screening tests and antibiotic treatments, the next step is to design an organized program for implementation. The term "organized" indicates that in a screening program, it is essential to let everyone have an equal opportunity to participate and to ensure that if a screening test result is abnormal, each subject can receive correct, standardized diagnostic testing and treatment. ${ }^{59}$ The process may include protocols to define and invite the target populations, to refer those who tested positive to receive standard treatment, to audit the quality of screening, and to assess patient adherence to treatment and side effects related to treatment.

\section{Defining the target population}

When the decision has been made to start eradication, the considerations may include whether to originally target the entire population, to target high risk populations, or to prevent new cases. $H$. pylori infections are typically acquired in childhood such that $H$. pylori eradication of young individuals before marriage would largely prevent transmission to their children and within several generations the disease would largely disappear. Also, this population has the highest proportion with nonatrophic gastritis and after the eradication therapy, the follow-up endoscopic surveillance is rarely needed. One would need to also ask whether to treat children and if so at what age. Screening would identify infected parents and thus identify families at greatest risk of having children with the infection. Reduction in the population burden of infection would also markedly reduce the chance of reinfection as the infection is almost exclusively restricted to humans.

However, in the real-world setting, an ideal design may be constrained by limitations in the framework for the delivery of screening tests or the system for providing treatment. For example, in Matsu Island, ${ }^{10}$ the residents had a high prevalence of $H$. pylori infection. The incidence of gastric cancer was about 50 cases per 100,000 person-years, which was approximately 3 to 5 times the incidence on Taiwan Main Island. H. pylori eradication would be expected to nearly eliminate the risk of gastric cancer in those with nonatrophic gastritis (most of whom would be younger persons) and stabilizing or reducing the risk among those with established atrophic damage (concentrated among older persons). The eligible age-range was set at 30 years and older (n=approximately 5,000) with the aim of accelerating the elimination of gastric cancer in this population. By contrast, in the Changhua County Study on the main Island of Taiwan, the incidence of gastric cancer was about 17 per 100,000 subjects per year. ${ }^{11}$ Because the carcinogenic process was believed to be slower than that on Matsu Island, the decision was not to initially target young adults; the eligible age range was set at 50 to 69 years. In addition, because the number of eligible subjects was large (n=approximately 260,000), it was important to perform the screening test as economically as possible. Therefore, the SAT was selected and added to the established protocol for colorectal cancer screening with the fecal immunochemical test. This program demonstrated an easy-to-implement approach for an intermediate-risk population for gastric cancer while the efficacy of this approach requires further observation.

\section{Recruiting the eligible population}

A cancer-screening program can easily fail without adequate participation. The relationship of adherence and effectiveness of a program can be expressed as follows:

Effectiveness of a program=efficacy of antibiotic treatment $\times$ adherence

Lower adherence will result in lower effectiveness of the screening program in preventing gastric cancer even when the intervention is highly efficacious. In both programs in Taiwan, potential participants were contacted either by telephone or with a pamphlet sent by mail, inviting them to participate in screening. Furthermore, as is the case with most cancer prevention programs, advertising and educational materials are helpful (an example available at http://epaper.ntuh.gov.tw/health/201208/ special_1_1.html). Such materials may improve participation by illustrating the purpose of screening and describing the followup diagnostics when screening tests show positive results.

\section{Auditing the quality of screening}

To ensure the quality of an organized screening program, it is mandatory to check whether the guidelines are being followed and that the results of the screening program are being regularly reported and evaluated. To reach this goal, a series of consensus meetings should be held to develop the treatment guidelines. Educational programs should be provided to both primary care physicians and first-line healthcare workers before implementation. After implementation, standardized quality indicators should be audited periodically to ensure the quality of screening. ${ }^{38}$ In the first round in the Chunghua program, ${ }^{11}$ among 3,621 tested subjects, the return rate of fecal samples was 95.4\%, the positivity rate of SAT was $36.2 \%$, and the referral rate for antibiotic treatment of those who tested positive was approximate $70 \%$. The eradication rate of first-line therapy was approximate $88 \%$. Among the 643 subjects also undergoing upper endoscopy, the PPV of SAT positivity (i.e., number with lesions/total number of diagnostic endoscopies) for gastrointestinal tract lesions was 31.9\% and the detection rate was 5.9\% (i.e., number with lesions/tested population). These indicator variables were periodically checked for outliers among the 26 townships. 


\section{Assessing the adherence to treatment and side effects of antibiotic treatment}

The optimal regimen for treating the asymptomatic population within the community remains unclear. Previous studies evaluating the efficacy of $H$. pylori eradication focused mainly on symptomatic subjects who were recruited from hospitals. Researchers tended to increase the duration of treatment and the number of antibiotics in order to increase the eradication rate; however, this practice should be weighed against decreased adherence in asymptomatic carriers because they are less likely to tolerate the length and complexity of the antimicrobial regimen. Adherence to the antibiotic treatment is crucial for the success of this program.

In the two prevention programs in Taiwan, first-line triple therapies consistently showed an eradication rate of approximate $88 \%$, given the antibiotic-resistance rates of approximately 1\%, 8.2\%, 3.8\%, 21.6\%, and 0.3\% for amoxicillin, clarithromycin, levofloxacin, metronidazole, and tetracycline, respectively. ${ }^{7}$ In many areas that results might be considered sufficient for treatment of the population. However, in Taiwan a retest-andretreat practice was utilized to improve the overall eradication and minimize the possible spread of antibiotic-resistant strains. $^{7,10,42}$ The second-line treatment, utilized a levofloxacincontaining triple therapy for 10 days that provides an approximately $80 \%$ eradication rate resulting in an overall eradication rate of approximately 98\% after two courses of treatments. For those who did not respond to the two courses of treatment (2/100), a tailored rescue regimen was designed on the basis of drug susceptibility testing..$^{60}$ For a country-wide test-and-treat strategy, it would be important to examine the cost effectiveness of regimens with a higher initial yield such as concomitant therapy for initial therapy and 14-day levofloxacin triple therapy for treatment failures provided that $100 \%$ eradication was shown to be a cost effective goal.

In addition to antibiotic resistance of $H$. pylori, incomplete adherence to treatment is an issue that warrants attention. To improve adherence, a call center has been set up in Changhua County., ${ }^{711}$ The personnel at the call center are equipped to evaluate the eradication rate of a specific regimen using the intention to treat (ITT) and per protocol (PP) analyses. For example, the eradication rates of the triple therapy for 7 days for the ITT and PP analyses were $88.1 \%$ and $89.0 \%$, respectively. For sequential therapy for 10 days, the eradication rates were both $2 \%$ higher, reaching a level that can be regarded as a good eradication rate (i.e., >90\%). ${ }^{61}$ Studies of different strategies in terms of eradication, adherence and cost effectiveness could easily be done as part of the initial implementation of a population-wide program.

The reinfection rate of $H$. pylori, which has the potential to overturn the effectiveness of this strategy, should be monitored by periodically testing those who had undergone successful eradication. In Matsu Island, the reinfection rate has been estimated to be about 1\% per person-year during 2004 to $2008 .^{10}$ This rate declined to $0.67 \%$ per person-year during 2008 to $2012,{ }^{7}$ a decline that appeared in parallel with improvements in sanitation and hygiene in this population. However, a proportion of those with apparent reinfection are actually recrudescence as in a small proportion of subjects treatment results in prolonged suppression and false-negative test of cure results. This can be reduced by employing more effective regimens initially.

\section{TRACKING THE OUTCOME}

In order to ensure continuous support from policy-makers/ stakeholders, evaluation of outcomes is necessary. In such an evaluation, the goals should be clearly defined, and data gathering and analysis should be performed in a timely manner. The outcomes may be categorized into the short-term end-points (e.g., surrogate outcome with premalignant gastric lesions), long-term end-points (e.g., gastric cancer incidence and mortality rate), cost-effectiveness analysis, and potential adverse effects.

\section{Short-term and long-term end-points}

In Matsu Island, the screening program applied a quasiexperimental, before-and-after study design, designating the whole population of Taiwan as an external comparator group. ${ }^{10}$ The main outcome measure was the impact of mass eradication on the changes of premalignant gastric lesions and gastric cancer, which was obtained by comparing data from the preand posteradication program eras in the same population. The results showed that the effectiveness of reducing the incidence of gastric atrophy and peptic ulcer was significant at $77.2 \%$ and $67.4 \%$, respectively; the reduction in incidence of gastric cancer was $25 \%$ although it was not statistically significant. To date, there are four rounds of mass eradication implemented in this population in 2004, 2008, 2012, and 2014, and the prevalence of $H$. pylori declined steadily from $60 \%$ to approximate $10 \%{ }^{7}$ We predict that a significant risk reduction of $47 \%$ will be observed in 2015.

In Changhua County, following the design of Matsu Gastric Cancer Prevention program, a pilot study was implemented in 2012. Among 7,463 participants during a 2-year period, the positivity rate of SAT was $34.4 \%$ with a referral rate of approximate 75\%. Among the referrals, antibiotic treatment was prescribed to $99 \%$, and five gastric cancers were found. ${ }^{7}$ Using the pilot study as a model, a randomized controlled study was launched in 2014 with inclusion of 10,000 subjects per year in each arm, and primary end-points of incident gastric cancer and death. 


\section{Cost-effectiveness analysis}

Not every proposed strategy can be realized at the population level, even though there is incontrovertible evidence to support the effectiveness of the strategy. The greatest impediment to widespread implementation is the fact that the proposed strategy may be costly, thus reducing its competitiveness with other health priorities. To address this problem, it requires costeffectiveness analyses (CEA). ${ }^{62}$

In the CEA, the first step is to create a model to simulate the natural history of the disease in the absence of screening, in which the parameters are generated from empirical studies of the specific population. The second step is to compare the natural course model (i.e., null hypothesis) with active screening (i.e., alternative hypothesis); taken together, these models constitute a decision model. Third, by inputting both the effectiveness and cost data into the decision model, the ratio of change in cost to the change in effect can be calculated (i.e., the incremental costeffectiveness ratio [ICER]) between different strategies. We can also make a projection of the long-term outcome (i.e., Markov model) without the requirements of a large sample size and long-term follow-up, and without ethical issues that may hinder the performance of an RCT. Fourth, by specifying distributions for all relevant parameters, the uncertainty in this model can be presented as an acceptability curve, which can provide the probability of each intervention being cost-effective according to different levels of the maximal willingness to pay (WTP) for a specific outcome. The final step involves varying the input of a parameter in the model by a given amount and examining whether the model's results will change (i.e., the sensitivity analysis). From the public health perspective, a one-size-fits-all intervention may not be optimal, and the purpose of a sensitivity analysis is to inspect whether a fine-adjustment of strategy is needed to make the screening program work well on the population level, which is, in fact, composed of diverse subpopulations.

In Taiwan, the CEA has been adopted in the evaluation of costs in curing $H$. pylori infection ${ }^{44}$ as well as in the prevention of death from gastric cancer. ${ }^{63}$ With regards to the former, the relative cost-effectiveness has been evaluated between twoantibiotic and three-antibiotic therapies. Results based on the base-case values showed a higher treatment efficacy for sequential therapy for 14 days than for triple therapy for 14 days. Sensitivity analyses according to prevalence of antibiotic-resistant strains showed that sequential therapy for 14 days was the more efficacious regimen (compared to triple therapy) in all areas, except in areas with very low $(<5 \%)$ clarithromycin resistance and very high $(>80 \%)$ metronidazole resistance; sequential therapy for 10 days appeared to be more effective than triple therapy for 14 days only in areas where the metronidazole resistance was $<40 \%$. Taking cost into consideration (Fig. 3A), the triple therapy for 14 days was found with a low $(<5 \%)$ possibility of being cost-effective. The sequential therapy for 10 days was the more cost-effective across a wide range of WTPs, while the same regimen for 14 days could be an alternative choice when the WTP is high. It is important to note that these analyses were restricted to two regimens and did not compare regimens such as concomitant or hybrid therapy which are often superior to sequential therapy in specific populations.

With regards to the prevention of gastric cancer, cost-effec-
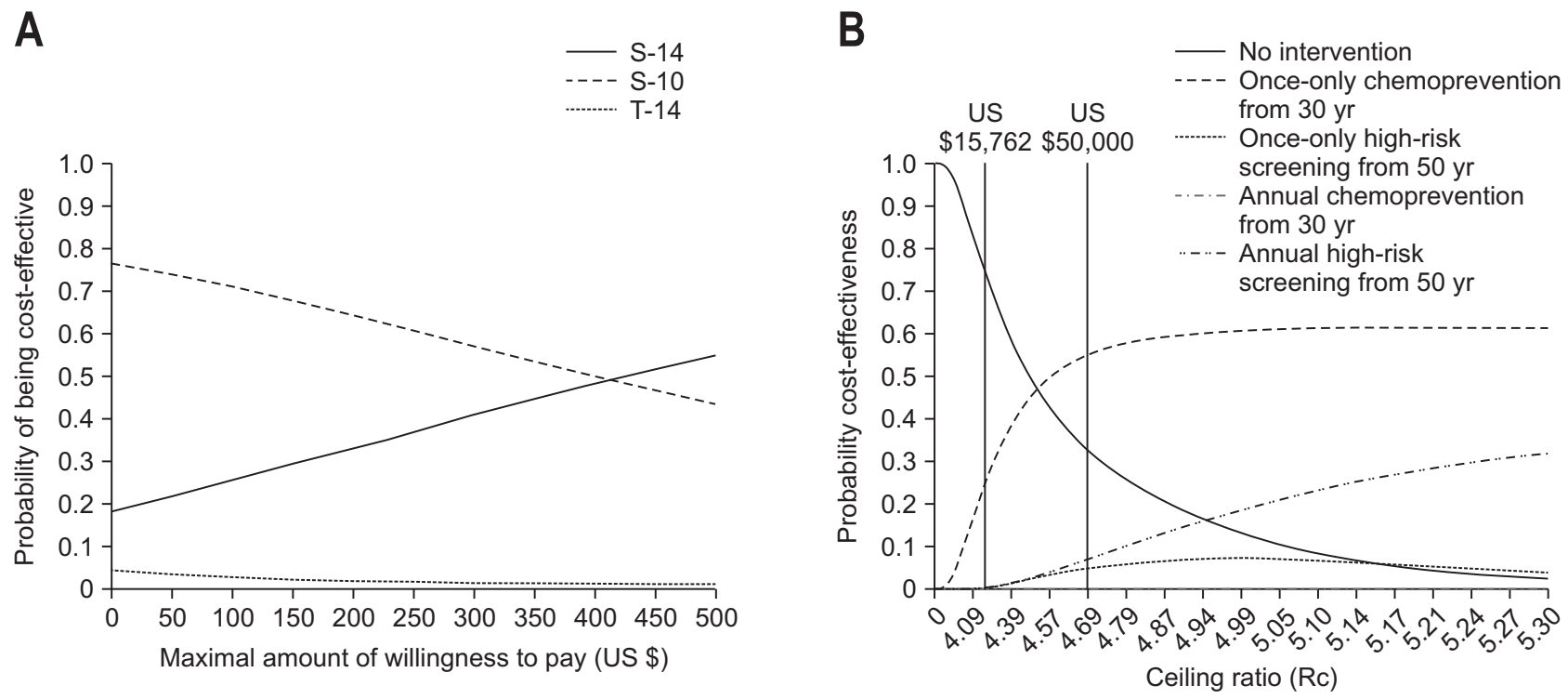

Fig. 3. Cost-effectiveness analysis comparing different regimens/strategies using acceptability curves: (A) the choice between sequential and triple therapies in the treatment of $H$. pylori infection and (B) the choice between screen-and-treat for $H$. pylori infection and endoscopic screening based on the serum pepsinogen method to prevent death from gastric cancer. Adapted from Liou JM, et al. Lancet 2013;381:205-213, ${ }^{44}$ and Lee YC, et al. Cancer Epidemiol Biomarkers Prev 2007;16:875-885. ${ }^{63}$ 


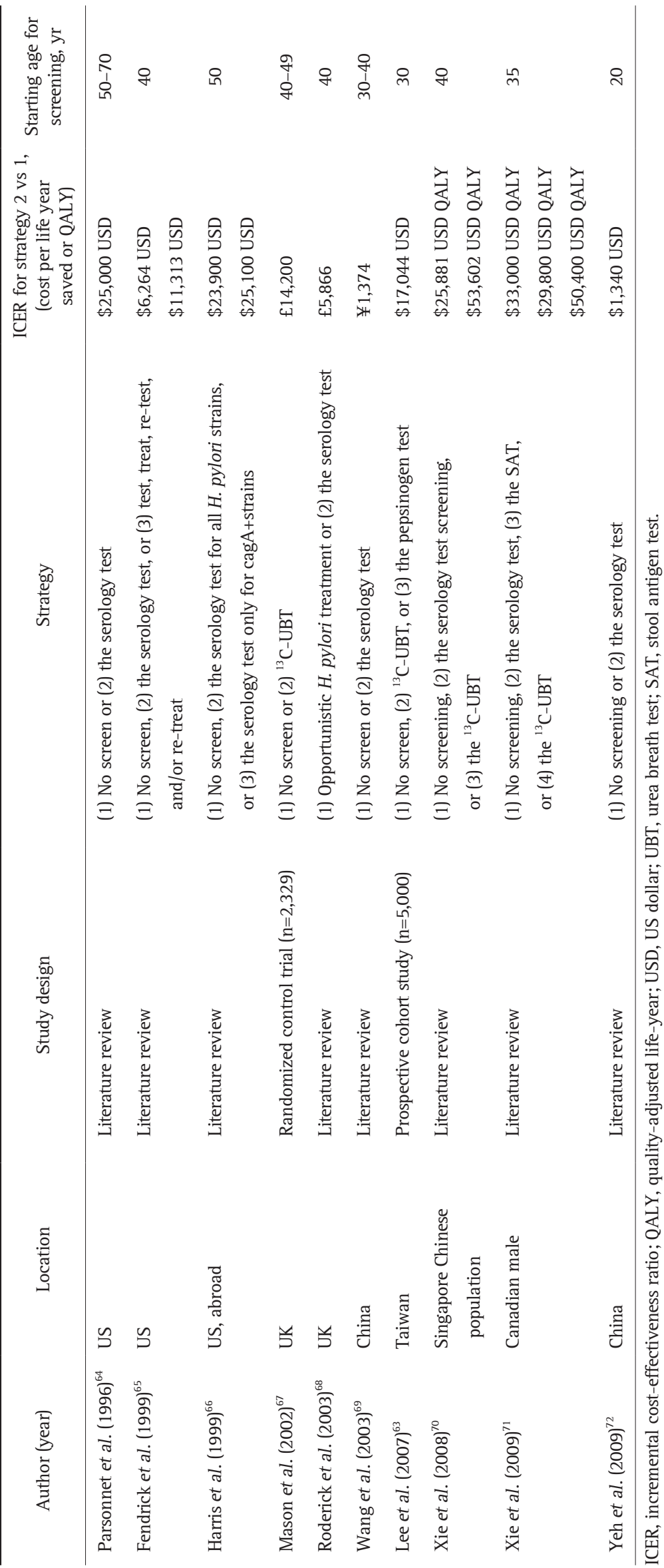


tiveness of the screen-and-treat strategy has been evaluated on a global scale (Table 4). ${ }^{63-72}$ When compared with no screen, this strategy was generally considered to be cost-effective, and there was a trend towards recommending a younger age for initiation of screening. Among the various subpopulations to be considered are those at risk of transmission to children (an elimination of transmission subgroup), those with nonatrophic gastritis (almost complete prevention of gastric cancer subgroup), and those with atrophic gastritis (a reduction in gastric cancer subgroup). Each may require a different strategy.

It deserves mention that all studies may have underestimated the relative cost-effectiveness of mass eradication because the benefit of reducing dyspepsia and peptic ulcers and transmission was not take into consideration. ${ }^{73}$ In Taiwan, the economic evaluation has been performed for the high-risk population residing on Matsu Island, comparing the screen-and-treat for $H$. pylori infection approach with traditional endoscopic screening based on the pepsinogen method (Fig. 3B). ${ }^{63}$ Within the acceptable range of WTP for a life-year gain, once-only $H$. pylori eradication at the younger age was the most cost-effective. In addition to recommending an initial screening age, sensitivity analyses showed that the relative cost-effectiveness was subject to the risk of $H$. pylori reinfection and endoscopic quality in detecting early gastric cancer, suggesting that the choice is also dependent on the socioeconomic status of a given subpopulation.

\section{Evaluation of adverse effects}

Some studies have suggested that the widespread eradication of $H$. pylori may lead to unforeseen dangers, such as increases in gastroesophageal reflux disease, childhood asthma and atopy, obesity, inflammatory bowel disease, and the activation of latent tuberculosis. ${ }^{74-78}$ However, there are confounders in all studies, and the underlying mechanism may not follow the presumed causal pathway (Fig. 4). This issue has been discussed in detail and the overall conclusion is that there is no current evidence that $H$. pylori infection provides a personal or population benefits. $^{79}$

In Taiwan, the prevalence of endoscopic esophagitis was found to increase following mass eradication in Matsu Island population, an area where atrophic gastritis is highly prevalent. ${ }^{10}$ The presumed mechanism may be related to the regeneration of gastric glands after the elimination of $H$. pylori, increased intragastric acid output, and more acid reflux into the esophagus; however, obesity may be a confounder. ${ }^{80}$ Furthermore, a reduction in gastric cancer risk can definitely outweigh this potential drawback, and low-grade erosive esophagitis can be managed by lifestyle modification such as weight loss (if indicated), avoidance of nicotine, alcohol, and smoking, and the use of short-course or on-demand acid-suppressing therapy. Also, this observation may be subject to the extent of gastric atrophy in the baseline gastric histology; a previous meta-analysis based mostly on populations at low-risk for gastric cancer has shown that there was no association between $H$. pylori eradication and development of new cases of gastroesophageal reflux disease in subjects with dyspepsia. ${ }^{81}$

\section{ISSUES AFTER MASS ERADICATION OF H. PYLORI}

After the mass eradication program, proper allocation of endoscopic resources is an important issue. The purpose of endoscopic screening is to find gastric cancer during the PCDP when curative treatment may be possible; however, although $H$. pylori is a well-recognized risk factor for gastric cancer, the use of $H$. pylori alone as a screening test may be insufficient for the detection of gastric cancer because the false-positive rate tends to be high. ${ }^{82}$ In the two preventive programs in Taiwan, ${ }^{10,11}$ in addition to antibiotic treatment, upper endoscopy was recommended for the $H$. pylori carriers 50 years of age or older, in order to increase the pretest probability of gastric cancer and hence, to increase the PPV of endoscopy. A previous CEA targeting a moderate to high-risk population (Singapore men, age-standardized rate for gastric cancer: 25.9/100,000) has suggested that $H$. pylori testing and biennial endoscopic screening for those who tested positive was cost-effective in persons 50 to 70 years of age. ${ }^{83}$ It is more logical to use the presence of atrophic gastritis rather than age to identify the target population. Surveillance can only benefit those with atrophic gastritis (i.e.,
Confounder (no role in the hypothetical mechanism of $H$. pylori to
Associated inversely or directly with $H$. pylori

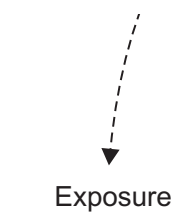

(H. pylori infection) disease)

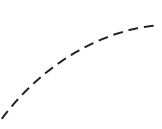

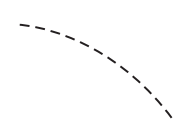

Associated with the disease

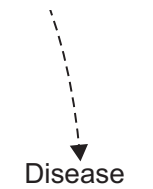

(gastroesophageal reflux, asthma, atopy, obesity, etc.)
Fig. 4. The presence of confounders in the observed relationship between Helicobacter pylori infection and extragastric diseases. 
those with risk remaining after $H$. pylori eradication) which is a small subset of the population. ${ }^{84}$ Those with significant atrophy (i.e., Operative Link on Gastritis Assessment system stage 3 or 4) retain significant risk despites eradication; they may benefit from endoscopic surveillance. ${ }^{85}$

To evaluate the effect of $H$. pylori eradication on gastric cancer prevention, the meta-analysis reviewed six RCTs showed a significant risk reduction of 34\% (95\% confidence interval [CI], 5\% to 54\%). ${ }^{31}$ However, although such an estimate reached statistical significance, it was actually imprecise, with a wide 95\% CI. Regarding tertiary prevention studies, a meta-analysis based on 13 studies showed a significant risk reduction of 58\% with a narrower $95 \% \mathrm{CI}$ of $44 \%$ to $68 \% ;^{32}$ however, only two RCTs were available so the risk of bias could not be excluded. ${ }^{86}$ Therefore, several preventive programs of different designs are ongoing in Eastern Asia and Europe. ${ }^{7}$ In Shandong Province, China, a clinical trial enrolling 200,000 residents (25 to 54 years of age) was launched in 2011, which allocated subjects to treatment and placebo groups. In Korea, starting in 2014, a randomized trial enrolled subjects aged 40-60 to undergo upper endoscopy, and those who tested positive for $H$. pylori infection were randomized to treatment and placebo groups (NCT02112214). In Europe, starting in 1997, a randomized trial in the United Kingdom allocated men aged 35 to 69 and women aged 45 to 69 to the screen or no-screen group for $H$. pylori infection.

It is likely that most studies will be stopped prematurely as they were based on the concept that it was necessary to prove that $H$. pylori caused gastric cancer and that question has been answered. Continuation of follow-up of the placebo treatment groups may likely soon be deemed to be unethical. In Japan, following the institution of reimbursement for eradication of $H$. pylori in persons with chronic gastritis in 2013, a serological method has been proposed to stratify subjects 40 years of age or older using the serological measurement of both $H$. pylori antibody and pepsinogen. Starting 2013, a multinational study enrolled subjects aged 50 or more to undergo a serological test with pepsinogen, gastrin-17, and $H$. pylori antibody to test the risk of gastric cancer at the time when subjects underwent colonoscopic screening (NCT02047994). Certainly, the use of endoscopy not only will depend on the gastric cancer risk of the target population, but also be subject to the local capacity for endoscopy, the cost of endoscopy, and the expertise of the endoscopist in detecting gastric cancer, and thus, will vary from country to country. ${ }^{87}$ There is a trend to place more emphasis on the implementation of a screen-and-treat strategy and on efficient allocation of endoscopic resources, rather than merely on how much benefit the eradication therapy will generate.

\section{CONCLUSIONS}

Awareness that gastric cancer is an infection-associated disease has been increasing worldwide, and gastric cancer, once a dreaded disease for which endoscopy provided the only hope of early detection, is gradually becoming a preventable disease through a short-course antibiotic treatment. In the past 30 years, compelling progress in the development of non-invasive tests to identify active infection, the ability to culture $H$. pylori, efficiency in the evaluation of antibiotic susceptibility, development of effective antimicrobial therapies, confirmation of the role of $H$. pylori in gastritis-associated peptic ulcer disease and gastric cancer, and proof that eradication of $H$. pylori could eliminate those diseases, have established a strong basis for the application of widespread $H$. pylori eradication programs. ${ }^{88}$ Henceforth, continuous effort should be made by spurring the government to take action on the elimination of gastric cancer from high prevalence areas through the design, implementation, monitoring, and outcome evaluation of an organized mass-eradication program.

\section{CONFLICTS OF INTEREST}

Dr. Graham is a consultant for RedHill Biopharma regarding novel $H$. pylori therapies and has received research support for culture of $H$. pylori. He is a consultant for Otsuka Pharmaceuticals regarding diagnostic breath testing and for BioGaia in relation to probiotic therapy for $H$. pylori infection. Other authors do not have conflicts of interest.

\section{ACKNOWLEDGEMENTS}

This study was supported by the Health Promotion Administration, Ministry of Health and Welfare (MOHW103TDU-212-114009) and National Taiwan University Hospital (104-P01). The funding source had no role in study design, data collection, analysis, or interpretation, report writing, or the decision to submit this paper for publication.

\section{REFERENCES}

1. Jemal A, Bray F, Center MM, Ferlay J, Ward E, Forman D. Global cancer statistics. CA Cancer J Clin 2011;61:69-90.

2. Ferlay J, Soerjomataram I, Dikshit R, et al. Cancer incidence and mortality worldwide: sources, methods and major patterns in GLOBOCAN 2012. Int J Cancer 2015;136:E359-E386.

3. Herrero R, Parsonnet J, Greenberg ER. Prevention of gastric cancer. JAMA 2014;312:1197-1198.

4. Park JY, von Karsa L, Herrero R. Prevention strategies for gastric cancer: a global perspective. Clin Endosc 2014;47:478-489.

5. Nobelprize.org. All nobel prizes in physiology or medicine [Internet]. Stockholm: Nobel Media AB; c2015 [cited 2015 Jan 26]. Available from: http://www.nobelprize.org/nobel_prizes/medicine/ laureates/.

6. Fox JG, Wang TC. Inflammation, atrophy, and gastric cancer. J Clin Invest 2007;117:60-69. 
7. IARC Helicobacter pylori Working Group. Helicobacter pylori eradication as a strategy for preventing gastric cancer (IARC Working Group Reports, No. 8) [Internet]. Lyon: International Agency for Research on Cancer; 2014 [cited 2015 Nov 9]. Available from: http:// www.iarc.fr/en/publications/pdfs-online/wrk/wrk8/index.php.

8. Sugano K, Tack J, Kuipers EJ, et al. Kyoto global consensus report on Helicobacter pylori gastritis. Gut 2015;64:1353-1367.

9. Graham DY, Shiotani A. The time to eradicate gastric cancer is now. Gut 2005;54:735-738.

10. Lee YC, Chen TH, Chiu HM, et al. The benefit of mass eradication of Helicobacter pylori infection: a community-based study of gastric cancer prevention. Gut 2013;62:676-682.

11. Lee YC, Chiu HM, Chiang TH, et al. Accuracy of faecal occult blood test and Helicobacter pylori stool antigen test for detection of upper gastrointestinal lesions. BMJ Open 2013;3:e003989.

12. Wilson JM, Jungner G. Principles and practice of screening for disease. WHO Chron 1968;22:473.

13. Taiwan Cancer Registry. Cancer statistics [Internet]. Taipei: Taiwan Cancer Registry; c2008 [cited 2015 Jan 5]. Available from: http:// crs.cph.ntu.edu.tw/main.php.

14. Bray F, Ren JS, Masuyer E, Ferlay J. Global estimates of cancer prevalence for 27 sites in the adult population in 2008. Int J Cancer 2013;132:1133-1145.

15. Wu GH, Auvinen A, Määttänen L, et al. Number of screens for overdetection as an indicator of absolute risk of overdiagnosis in prostate cancer screening. Int J Cancer 2012;131:1367-1375.

16. Yachida S, Jones S, Bozic I, et al. Distant metastasis occurs late during the genetic evolution of pancreatic cancer. Nature 2010; 467:1114-1117.

17. Patz EF Jr, Pinsky P, Gatsonis C, et al. Overdiagnosis in low-dose computed tomography screening for lung cancer. JAMA Intern Med 2014;174:269-274.

18. Sanduleanu S, Le Clercq CM, Dekker E, et al. Definition and taxonomy of interval colorectal cancers: a proposal for standardising nomenclature. Gut 2015;64:1257-1267.

19. Chiang TH, Chuang SL, Chen SL, et al. Difference in performance of fecal immunochemical tests with the same hemoglobin cutoff concentration in a nationwide colorectal cancer screening program. Gastroenterology 2014;147:1317-1326.

20. Garland SM, Hernandez-Avila M, Wheeler CM, et al. Quadrivalent vaccine against human papillomavirus to prevent anogenital diseases. N Engl J Med 2007;356:1928-1943.

21. Chang MH, Chen CJ, Lai MS, et al. Universal hepatitis B vaccination in Taiwan and the incidence of hepatocellular carcinoma in children. Taiwan Childhood Hepatoma Study Group. N Engl J Med 1997;336:1855-1859.

22. de Martel C, Ferlay J, Franceschi S, et al. Global burden of cancers attributable to infections in 2008: a review and synthetic analysis. Lancet Oncol 2012;13:607-615.

23. Wong BC, Lam SK, Wong WM, et al. Helicobacter pylori eradication to prevent gastric cancer in a high-risk region of China: a randomized controlled trial. JAMA 2004;291:187-194.
24. Correa P, Fontham ET, Bravo JC, et al. Chemoprevention of gastric dysplasia: randomized trial of antioxidant supplements and antihelicobacter pylori therapy. J Natl Cancer Inst 2000;92:1881-1888.

25. Mera R, Fontham ET, Bravo LE, et al. Long term follow up of patients treated for Helicobacter pylori infection. Gut 2005;54:15361540.

26. You WC, Brown LM, Zhang L, et al. Randomized double-blind factorial trial of three treatments to reduce the prevalence of precancerous gastric lesions. J Natl Cancer Inst 2006;98:974-983.

27. Li WQ, Ma JL, Zhang L, et al. Effects of Helicobacter pylori treatment on gastric cancer incidence and mortality in subgroups. J Natl Cancer Inst 2014;106. pii: dju116.

28. Leung WK, Lin SR, Ching JY, et al. Factors predicting progression of gastric intestinal metaplasia: results of a randomised trial on Helicobacter pylori eradication. Gut 2004;53:1244-1249.

29. Zhou L. Ten-year follow-up study on the incidence of gastric cancer and the pathological changes of gastric mucosa after $\mathrm{H}$. pylori eradication in China. Gastroenterology 2008;134(4 Suppl 1):A233.

30. Fukase K, Kato M, Kikuchi S, et al. Effect of eradication of Helicobacter pylori on incidence of metachronous gastric carcinoma after endoscopic resection of early gastric cancer: an open-label, randomised controlled trial. Lancet 2008;372:392-397.

31. Ford AC, Forman D, Hunt RH, Yuan Y, Moayyedi P. Helicobacter pylori eradication therapy to prevent gastric cancer in healthy asymptomatic infected individuals: systematic review and metaanalysis of randomised controlled trials. BMJ 2014;348:g3174.

32. Yoon SB, Park JM, Lim CH, Cho YK, Choi MG. Effect of Helicobacter pylori eradication on metachronous gastric cancer after endoscopic resection of gastric tumors: a meta-analysis. Helicobacter 2014;19:243-248.

33. Malfertheiner P, Megraud F, O'Morain CA, et al. Management of Helicobacter pylori infection: the Maastricht IV/ Florence Consensus Report. Gut 2012;61:646-664.

34. Granstrom M, Lehours P, Bengtsson C, Mégraud F. Diagnosis of Helicobacter pylori. Helicobacter 2008;13 Suppl 1:7-12.

35. Gisbert JP, de la Morena F, Abraira V. Accuracy of monoclonal stool antigen test for the diagnosis of H. pylori infection: a systematic review and meta-analysis. Am J Gastroenterol 2006;101: 1921-1930.

36. Lee YC, Tseng PH, Liou JM, et al. Performance of a one-step fecal sample-based test for diagnosis of Helicobacter pylori infection in primary care and mass screening settings. J Formos Med Assoc 2014;113:899-907.

37. Loy CT, Irwig LM, Katelaris PH, Talley NJ. Do commercial serological kits for Helicobacter pylori infection differ in accuracy? A meta-analysis. Am J Gastroenterol 1996;91:1138-1144.

38. Benson VS, Atkin WS, Green J, et al. Toward standardizing and reporting colorectal cancer screening indicators on an international level: the International Colorectal Cancer Screening Network. Int J Cancer 2012;130:2961-2973.

39. Porras C, Nodora J, Sexton R, et al. Epidemiology of Helicobacter pylori infection in six Latin American countries (SWOG Trial 
S0701). Cancer Causes Control 2013;24:209-215.

40. Greenberg ER, Anderson GL, Morgan DR, et al. 14-day triple, 5-day concomitant, and 10-day sequential therapies for Helicobacter pylori infection in seven Latin American sites: a randomised trial. Lancet 2011;378:507-514.

41. Peleteiro B, Bastos A, Ferro A, Lunet N. Prevalence of Helicobacter pylori infection worldwide: a systematic review of studies with national coverage. Dig Dis Sci 2014;59:1698-1709.

42. Lee YC, Wu HM, Chen TH, et al. A community-based study of Helicobacter pylori therapy using the strategy of test, treat, retest, and retreat initial treatment failures. Helicobacter 2006;11:418424.

43. Graham DY, Dore MP. Variability in the outcome of treatment of Helicobacter pylori infection: a critical analysis. In: Hunt RH, Tytgat GN, eds. Helicobacter pylori: basic mechanisms to clinical cure 1998. Dordrecht: Springer, 1998:426-440.

44. Liou JM, Chen CC, Chen MJ, et al. Sequential versus triple therapy for the first-line treatment of Helicobacter pylori: a multicentre, open-label, randomised trial. Lancet 2013;381:205-213.

45. Graham DY, Lee YC, Wu MS. Rational Helicobacter pylori therapy: evidence-based medicine rather than medicine-based evidence. Clin Gastroenterol Hepatol 2014;12:177-186.e3.

46. Lee SY. Current progress toward eradicating Helicobacter pylori in East Asian countries: differences in the 2013 revised guidelines between China, Japan, and South Korea. World J Gastroenterol 2014;20:1493-1502.

47. Zullo A, Vaira D, Vakil N, et al. High eradication rates of Helicobacter pylori with a new sequential treatment. Aliment Pharmacol Ther 2003;17:719-726.

48. Romano M, Marmo R, Cuomo A, et al. Pretreatment antimicrobial susceptibility testing is cost saving in the eradication of Helicobacter pylori. Clin Gastroenterol Hepatol 2003;1:273-278.

49. Vaira D, Zullo A, Vakil N, et al. Sequential therapy versus standard triple-drug therapy for Helicobacter pylori eradication: a randomized trial. Ann Intern Med 2007;146:556-563.

50. Demir M, Gokturk HS, Ozturk NA, Arslan H, Serin E, Yilmaz U. Clarithromycin resistance and efficacy of clarithromycin-containing triple eradication therapy for Helicobacter pylori infection in type 2 diabetes mellitus patients. South Med J 2009;102:11161120.

51. Romano M, Cuomo A, Gravina AG, et al. Empirical levofloxacincontaining versus clarithromycin-containing sequential therapy for Helicobacter pylori eradication: a randomised trial. Gut 2010;59:1465-1470.

52. Wu DC, Hsu PI, Wu JY, et al. Sequential and concomitant therapy with four drugs is equally effective for eradication of $\mathrm{H}$ pylori infection. Clin Gastroenterol Hepatol 2010;8:36-41.e1.

53. Sirimontaporn N, Thong-Ngam D, Tumwasorn S, Mahachai V. Ten-day sequential therapy of Helicobacter pylori infection in Thailand. Am J Gastroenterol 2010;105:1071-1075.

54. Yakoob J, Abid S, Abbas Z, Jafri SN. Antibiotic susceptibility patterns of Helicobacter pylori and triple therapy in a high-prevalence area. Br J Biomed Sci 2010;67:197-201.

55. Hsu PI, Wu DC, Wu JY, Graham DY. Is there a benefit to extending the duration of Helicobacter pylori sequential therapy to 14 days? Helicobacter 2011;16:146-152.

56. Malfertheiner P, Bazzoli F, Delchier JC, et al. Helicobacter pylori eradication with a capsule containing bismuth subcitrate potassium, metronidazole, and tetracycline given with omeprazole versus clarithromycin-based triple therapy: a randomised, open-label, non-inferiority, phase 3 trial. Lancet 2011;377:905-913.

57. Mahachai V, Sirimontaporn N, Tumwasorn S, Thong-Ngam D, Vilaichone RK. Sequential therapy in clarithromycin-sensitive and -resistant Helicobacter pylori based on polymerase chain reaction molecular test. J Gastroenterol Hepatol 2011;26:825-828.

58. Molina-Infante J, Romano M, Fernandez-Bermejo M, et al. Optimized nonbismuth quadruple therapies cure most patients with Helicobacter pylori infection in populations with high rates of antibiotic resistance. Gastroenterology 2013;145:121-128.e1.

59. World Health Organization (WHO). What is an "organized" screening programme [Internet]. Geneva: WHO; 2015 [cited 2015 Dec 8]. Available from: http://cancer-code-europe.iarc.fr/index.php/en/ ecac-12-ways/screening-recommandation/key-points-about-cancer-screening/213-what-is-an-organized-screening-programme.

60. Liou JM, Chen CC, Chang CY, et al. Efficacy of genotypic resistance-guided sequential therapy in the third-line treatment of refractory Helicobacter pylori infection: a multicentre clinical trial. J Antimicrob Chemother 2013;68:450-456.

61. Graham DY, Fischbach L. Helicobacter pylori treatment in the era of increasing antibiotic resistance. Gut 2010;59:1143-1153.

62. Briggs AH, Goeree R, Blackhouse G, O’Brien BJ. Probabilistic analysis of cost-effectiveness models: choosing between treatment strategies for gastroesophageal reflux disease. Med Decis Making 2002;22:290-308.

63. Lee YC, Lin JT, Wu HM, et al. Cost-effectiveness analysis between primary and secondary preventive strategies for gastric cancer. Cancer Epidemiol Biomarkers Prev 2007;16:875-885.

64. Parsonnet J, Harris RA, Hack HM, Owens DK. Modelling costeffectiveness of Helicobacter pylori screening to prevent gastric cancer: a mandate for clinical trials. Lancet 1996;348:150-154.

65. Fendrick AM, Chernew ME, Hirth RA, Bloom BS, Bandekar RR, Scheiman JM. Clinical and economic effects of population-based Helicobacter pylori screening to prevent gastric cancer. Arch Intern Med 1999;159:142-148.

66. Harris RA, Owens DK, Witherell H, Parsonnet J. Helicobacter pylori and gastric cancer: what are the benefits of screening only for the CagA phenotype of H. pylori? Helicobacter 1999;4:69-76.

67. Mason J, Axon AT, Forman D, et al. The cost-effectiveness of population Helicobacter pylori screening and treatment: a Markov model using economic data from a randomized controlled trial. Aliment Pharmacol Ther 2002;16:559-568.

68. Roderick P, Davies R, Raftery J, et al. Cost-effectiveness of population screening for Helicobacter pylori in preventing gastric cancer and peptic ulcer disease, using simulation. J Med Screen 
2003;10:148-156.

69. Wang Q, Jin PH, Lin GW, Xu SR, Chen J. Cost-effectiveness of Helicobacter pylori screening to prevent gastric cancer: Markov decision analysis. Zhonghua Liu Xing Bing Xue Za Zhi 2003;24:135139.

70. Xie F, Luo N, Lee HP. Cost effectiveness analysis of populationbased serology screening and (13)C-Urea breath test for Helicobacter pylori to prevent gastric cancer: a markov model. World J Gastroenterol 2008;14:3021-3027.

71. Xie F, O’Reilly D, Ferrusi IL, et al. Illustrating economic evaluation of diagnostic technologies: comparing Helicobacter pylori screening strategies in prevention of gastric cancer in Canada. J Am Coll Radiol 2009;6:317-323.

72. Yeh JM, Kuntz KM, Ezzati M, Goldie SJ. Exploring the costeffectiveness of Helicobacter pylori screening to prevent gastric cancer in China in anticipation of clinical trial results. Int J Cancer 2009;124:157-166.

73. Ford AC, Forman D, Bailey AG, Axon AT, Moayyedi P. A community screening program for Helicobacter pylori saves money: 10year follow-up of a randomized controlled trial. Gastroenterology 2005;129:1910-1917.

74. Chow WH, Blaser MJ, Blot WJ, et al. An inverse relation between cagA+ strains of Helicobacter pylori infection and risk of esophageal and gastric cardia adenocarcinoma. Cancer Res 1998;58:588590.

75. Chen Y, Blaser MJ. Helicobacter pylori colonization is inversely associated with childhood asthma. J Infect Dis 2008;198:553-560.

76. Wu MS, Lee WJ, Wang HH, Huang SP, Lin JT. A case-control study of association of Helicobacter pylori infection with morbid obesity in Taiwan. Arch Intern Med 2005;165:1552-1555.

77. Papamichael K, Konstantopoulos P, Mantzaris GJ. Helicobacter pylori infection and inflammatory bowel disease: is there a link?
World J Gastroenterol 2014;20:6374-6385.

78. Perry S, de Jong BC, Solnick JV, et al. Infection with Helicobacter pylori is associated with protection against tuberculosis. PLoS ONE 2010;5:e8804.

79. Graham DY. Helicobacter pylori update: gastric cancer, reliable therapy, and possible benefits. Gastroenterology 2015;148:719731.e3.

80. Lee YC, Yen AM, Tai JJ, et al. The effect of metabolic risk factors on the natural course of gastro-oesophageal reflux disease. Gut 2009;58:174-181.

81. Yaghoobi M, Farrokhyar F, Yuan Y, Hunt RH. Is there an increased risk of GERD after Helicobacter pylori eradication? A meta-analysis. Am J Gastroenterol 2010;105:1007-1013.

82. Wald NJ, Hackshaw AK, Frost CD. When can a risk factor be used as a worthwhile screening test? BMJ 1999;319:1562-1565.

83. Dan YY, So JB, Yeoh KG. Endoscopic screening for gastric cancer. Clin Gastroenterol Hepatol 2006;4:709-716.

84. Shiotani A, Cen P, Graham DY. Eradication of gastric cancer is now both possible and practical. Semin Cancer Biol 2013;23(6 Pt B):492-501.

85. Rugge M, Correa P, Di Mario F, et al. OLGA staging for gastritis: a tutorial. Dig Liver Dis 2008;40:650-658.

86. Guyatt GH, Oxman AD, Vist G, et al. GRADE guidelines: 4. rating the quality of evidence: study limitations (risk of bias). J Clin Epidemiol 2011;64:407-415.

87. Choi HS, Lee SY, Kim JH, et al. Combining the serum pepsinogen level and Helicobacter pylori antibody test for predicting the histology of gastric neoplasm. J Dig Dis 2014;15:293-298.

88. Fock KM, Graham DY, Malfertheiner P. Helicobacter pylori research: historical insights and future directions. Nat Rev Gastroenterol Hepatol 2013;10:495-500. 